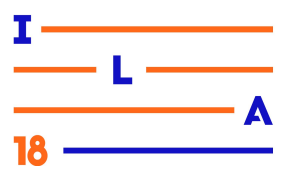

\title{
DESIGN SOCIAL E EMOCIONAL COMO FERRAMENTAS PARA INTERAÇÃO COM MULHERES EGRESSAS NO RIO
}

\section{SOCIAL AND EMOTIONAL DESIGN AS TOOLS FOR INTERACTING WITH WOMEN OUT OF PRISON IN RIO DE JANEIRO}

\author{
Alana Maganha ${ }^{1}$, Bach. \\ Raquel Ponte ${ }^{2}$, D.Sc. \\ (1) Universidade Federal do Rio de Janeiro, UFRJ \\ e-mail:alanamaganha@gmail.com \\ (2) Universidade Federal do Rio de Janeiro, UFRJ \\ e-mail: raquelponte@gmail.com
}

\begin{abstract}
Design emocional, design social, mulheres egressas, design centrado no indivíduo
Este artigo defende a aplicação do design social e do design emocional como ferramentas facilitadoras na interação com mulheres egressas do sistema prisional, exemplificado por meio de uma proposta de estratégia de comunicação visual para o Coletivo em Silêncio.
\end{abstract}

Emotional design, social design, women out of prison, human-centered design This article defends the use of social and emotional design as facilitation tools within the interaction with women recently out of prison, presenting as an example the communication strategy developed for Coletivo em Silencio.

\section{Introdução}

A participação do designer na solução de questões sociais e nas políticas públicas, atualmente ainda pouco expressiva, se mostra como um campo amplo a ser explorado, repleto de possibilidades e com muito potencial tanto de responsabilidade social quanto como forma de projetar com sucesso e eficiência fora dos moldes do mercado.

O designer, como profissional interdisciplinar, é capaz de agregar metodologias e estratégias com foco no indivíduo e em suas emoções, tornando projetos de cunho social e até mesmo questões de administração pública mais assertivos no objetivo de melhorar a interação com o público e solucionar problemas (BONSIEPE, 20013).

Destaca-se, em meio a tantas possibilidades, a chance do design contemplar e auxiliar públicos que necessitam de atenção especial (PAZMINO, 2007), por muitas vezes isolados pela própria sociedade que os cerca. Dentre estes, as mulheres encarceradas e egressas do sistema prisional do Rio de Janeiro chamam atenção pelas condições precárias em que sobrevivem dentro e, posteriormente, fora das prisões ${ }^{1}$.

Para entrar em contato com esse público, mostrou-se necessário buscar uma mediação. A partir da relação com o Coletivo em Silêncio, estudos foram desenvolvidos para atender as necessidades específicas ao projeto de ressocialização para mulheres egressas do sistema prisional que o grupo tenta implementar atualmente.

Às egressas são oferecidos oficinas e laboratórios com metodologias desenvolvidas pelo Coletivo. As oficinas trabalham a expressão

\footnotetext{
${ }^{1}$ Como descrito no relatório do MEPCT/RJ, Mulheres, Meninas e Privação de Liberdade no Rio de Janeiro, de 2016.
} 


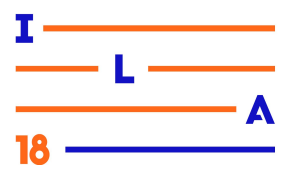

das egressas, conscientizando-as por meio de três módulos de atividades corporais com o intuito de dar voz a essas mulheres que foram desassociadas de sua identidade, sua cultura e seus valores. Já os laboratórios oferecem o ensino de atividades que permitam a geração de renda atreladas a valores educativos e sócio-ambientais, sendo um voltado para plantio e cultivo sustentável e outro com foco em cabelos e penteados afro.

Criando uma metodologia própria, o grupo propõe "alterar as marcas de violência impressas nos corpos das mulheres"2 , potencializando o corpo e a singularidade de cada egressa. Por meio de arte e criação, a intenção é incentivar possibilidades de sustento próprio e familiar digno, com preocupação de produção socialmente sustentável, e, em um escopo mais largo, ajudar na trajetória de efetiva descriminalização de raça, gênero e classe.

Mediante entrevistas, participações em reuniões e leituras de pautas antigas, identificou-se a necessidade que o Coletivo possuía de adquirir uma marca e identidade próprias e de desenvolver uma estratégia de comunicação para dialogar com as egressas.

Em casos como este, o design é capaz não somente de garantir comunicação e integração claras entre público e instituições, como restaurar bem-estar e confiança dessas mulheres em si mesmas e nas chances de reconstruir a vida em sociedade. Para isto, o design social e o design emocional se apresentam como peças de extrema relevância, potencializando os benefícios que se espera alcançar no projeto.

\section{Compreendendo o público}

\footnotetext{
${ }^{2}$ Segundo trecho de ata de reunião do Coletivo na qual elas debateram sobre definições de apresentação para o projeto para as egressas.
}

A quinta maior população de mulheres encarceradas no mundo em 2014 era a do Brasil ${ }^{3}$. Essa mesma população cresceu $567 \%$ entre 2000 e 2014, comparado aos $220 \%$ de crescimento da população carcerária masculina do país. Ainda que esses dados sejam preocupantes, essas mulheres são constantemente invisibilizadas, e pouco se discute sua situação enquanto presas (na maioria dos estados, extremamente precária) ou sua reinserção de maneira humanizada na sociedade, a fim de evitar a reincidência.

Diante de questões sociais tão preocupantes e imediatas como a situação das mulheres que retornam do sistema prisional em busca de reintegração social, o questionamento do papel do designer se faz presente.

\subsection{As mulheres presas e egressas no Rio}

Ao observar os dados da população feminina encarcerada no país, nota-se que o estado do Rio de Janeiro é o terceiro maior em população prisional no Brasil. No caso das mulheres presas, tem havido um grande crescimento no número de encarceradas no estado, segundo o relatório Mulheres, Meninas e Privação de Liberdade no Rio de Janeiro de 2016 lançado pelo MEPCT/RJ. Entre 2013 e 2014, existiu um crescimento de 1.618 para 4.139 mulheres presas no Rio.

É necessário dizer que pessoas em situação prisional são constantemente submetidas a desvinculação com a própria identidade, cultura e valores pessoais. Não somente o isolamento da sociedade civil e a perda dos direitos de ir e vir caracterizam as condições impostas a essas pessoas, como também a perda da autonomia e muitas vezes o apagamento das singularidades e potencialidades individuais abrem passagem para uma padronização comportamental e submissão extremas.

Se mostram muito preocupantes os relatos de precariedade, violência, ociosidade e solidão recolhidos pelo MEPCT/RJ a respeito dos

\footnotetext{
${ }^{3}$ Dado segundo Levantamento Nacional de Informações Penitenciárias - Infopen Mulheres Junho 2014
} 


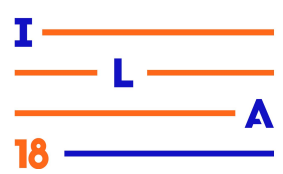

presídios no Rio. Nota-se que a população carcerária feminina é extremamente esquecida e invisibilizada pelo Estado e pela sociedade civil que a cerca, tornando-se ainda mais urgente a necessidade de projetos voltados para esse público. É importante lembrar que essas mulheres merecem os mesmos respeito e direitos humanos dos outros cidadãos, e que eventualmente elas terão seu regresso à sociedade "aqui fora".

Pensando nesse regresso das mulheres presas a sociedade e na subsistência a qual são submetidas ao longo do tempo de cárcere, é importante avaliar com seriedade e sensibilidade as condições de ressocialização existentes. Nesse momento, o design se faz necessário na identificação e construção de como interagir com essas mulheres a fim de evitar reincidências e garantir um regresso digno.

\subsection{Design com foco no indivíduo}

Atualmente, muitas vertentes do design entendem que o papel do designer é compreender e projetar para as pessoas e suas necessidades. Design thinking, design social, design de experiência, design de serviços e design emocional são exemplos de áreas na profissão que dialogam em prol desse entendimento. São muitos os profissionais que seguem essas metodologias e atuam nessas áreas e, consequentemente, acreditam que estamos aqui para servir e solucionar.

"Nós temos que parar de pensar em design como a construção de gráficos, produtos, serviços, sistemas e ambientes e pensar nessas coisas como meios para as pessoas agirem, realizar seus desejos e satisfazer suas necessidades. São os desejos e as necessidades a que nós devemos servir [...]." (FRASCARA, 2002, p. 33) ${ }^{4}$

${ }^{4}$ Livremente traduzido do original em ingles: "We have to stop thinking of design as the construction of graphics, products, services, systems and environments, and think about those as means for people to act, to realize their wishes and satisfy their
Partindo dessa premissa, não é aceitável que o profissional encare um projeto de comunicação visual apenas como uma maneira coesa e esteticamente agradável de informar, por exemplo. É necessário que haja um estudo do ambiente onde a comunicação será veiculada e um entendimento da cultura, dos conhecimentos gerais e do comportamento do público com o qual a comunicação travará um diálogo para, assim, efetivamente causar um impacto e ser relevante para esse público.

O design centrado no indivíduo é intrinsecamente interdisciplinar. Além de interdisciplinar, é uma maneira de projetar soluções em que não é possível saber o resultado final sem ter passado pelo processo. Dessa forma, um problema pode começar a ser avaliado a partir de uma área e, ao longo do projeto, ser solucionado por meio de ferramentas e metodologias de outra. Isso ocorre porque o reposicionamento do problema em outros enquadramentos e a partir de outros pontos de vista levanta novos questionamentos e ideias, possibilitando soluções mais eficazes.
"Somente ouvindo, pensando, construindo e refinando nosso caminho para uma resposta nós chegamos em algo que vai funcionar para as que estamos tentando servir." (IDEO.ORG, $2015)^{5}$

No mais, o foco no indivíduo parte da crença de que as pessoas que passam pelos problemas a serem solucionados são exatamente aquelas que vão dar as informações necessárias para o desenvolvimento de um projeto útil, eficaz e relevante.

\section{Design Social}

Além de compreender que um design eficiente parte do entendimento do indivíduo e da

needs. It is the needs and the wishes that we have to serve $[. .$.$] ."$

${ }^{5}$ Livremente traduzido do original em inglês: "Only by listening, thinking, building, and refining our way to an answer do we get something that will work for the people we're trying to serve." 


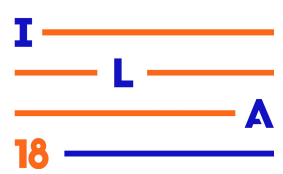

proposta de construir em conjunto, estudando, entrevistando e permitindo que o público apresente caminhos para a solução, é igualmente necessário saber identificar os problemas a serem abordados.

O design social explora problemas sistemáticos e, em grande parte, recorrentes em grupos de minorias. Nesses casos, os projetos buscam melhorias na qualidade de vida, renda e inclusão social, levantando um debate sobre o compromisso moral do designer ${ }^{6}$.

Como profissional interdisciplinar que tem por premissa solucionar problemas e servir às necessidades e vontades dos indivíduos, fica claro que a presença do designer em projetos sociais, na administração pública e em setores que dialogam e provêm para os cidadãos é de grande valia. Questiona-se, então, porque essas áreas são ainda pouco preenchidas pelos profissionais do ramo.

Embora esse artigo não consiga responder a este questionamento, é possível imaginar que um movimento crescente de designers interessados em projetar para a sociedade cause um impacto positivo na vida coletiva. Empreendimentos de comunicação e design como a Shoot This Shit (de Porto Alegre) ${ }^{7}$ e a Juntos (do Rio de Janeiro $)^{8}$, focados em causas e engajamento social, mostram que além de socialmente responsável, esses projetos também podem ser lucrativos.

\section{Emoção e sensações no design}

A prática do design emocional busca persuadir o público-alvo por meio da criação de laços emocionais com a marca. Uma das maneiras de construir esse vínculo é explorando os sentidos para além da visão a fim de criar uma percepção

\footnotetext{
${ }^{6}$ PAZMINO, 2007.

7 "Somos um Estúdio Criativo de Comunicação focado em projetos que geram impacto social positivo." Mais em: http://www.shoottheshit.cc/

8 "Somos uma agência de Comunicação que conecta propósitos, marcas e pessoas." Mais em:

http://www.agenciajuntos.com.br/
}

mais completa do projeto. Para Donald A. Norman, cientista e autor de Design Emocional: Por que adoramos (ou odiamos) os objetos do dia-a-dia (2008), emoções e cognição são inseparáveis, e juntas constroem um sistema de julgamento do que é bom e do que é ruim.

Ao projetar utilizando essa metodologia, o foco é que a peça ou serviço se equipare ou se sobreponha às expectativas do público, e que a sensação causada pela interação crie boas lembranças. Por isso, é necessário mais uma vez destacar a importância de se pensar no indivíduo e construir coletivamente a proposta, uma vez que uma solução que funcione para um público pode não ser entendida ou até mesmo preterida por outro.

No caso da aplicação da técnica no projeto com foco social desenvolvido ao longo deste artigo, a criação de uma atmosfera que propicie as egressas acreditarem que são bem quistas e que merecem uma oportunidade de ressocialização eficiente é de extrema importância para que as mesmas se interessem em participar. Ainda que o designer se apresente como um profissional interdisciplinar, um bom projeto social requer uma equipe de profissionais e, principalmente, humanos interessados em realizar uma mudança sensível e eficiente em seus propósitos.

Desta forma, mostra-se necessário criar vínculo com um grupo de pessoas que tenha um público de interesse comum - sendo, neste artigo, as egressas do sistema prisional do Rio de Janeiro.

\section{O Coletivo em Silêncio}

Para desenvolver uma proposta-exemplo da utilização do design como ferramenta facilitadora na interação com as mulheres egressas, estabeleceu-se contato com o Coletivo em Silêncio.

Majoritariamente constituído por mulheres, o coletivo tem profissionais de saúde, meio ambiente, direito, educação, cultura, artes e assistência social que também são donas de casa, mães, esposas, artistas, ativistas, militantes e 


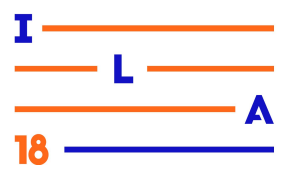

pesquisadoras envolvidas com os estudos e a ideia de propor ações e projetos com foco em mulheres encarceradas.

Ao observar a carência de abordagens psico-pedagógicas com foco nas mulheres presas, o Coletivo começou a desenvolver um projeto socio-econômico de laboratórios e oficinas para mulheres egressas, em regimes aberto e semi-aberto, ou em liberdade condicional. Tal projeto procura não somente reduzir a reincidência de mulheres que já cumpriram suas penas nas prisões por meio de uma metodologia de inclusão social, como, principalmente, restabelecer de maneira eficaz o convívio da egressa em sociedade, melhorando os laços destas com o trabalho, com as pessoas em volta, e consigo mesmas.

Às egressas são oferecidos oficinas e laboratórios com metodologias desenvolvidas pelo Coletivo. As oficinas trabalham a expressão das egressas, conscientizando-as por meio de três módulos de atividades corporais com o intuito de dar voz a essas mulheres que foram desassociadas de sua identidade, sua cultura e seus valores. Já os laboratórios oferecem o ensino de atividades que permitam a geração de renda atreladas a valores educativos e sócio-ambientais, sendo um voltado para plantio e cultivo sustentável e outro com foco em cabelos e penteados afro.

Criando uma metodologia própria, o grupo propõe "alterar as marcas de violência impressas nos corpos das mulheres" ${ }^{\prime 9}$, potencializando o corpo e a singularidade de cada egressa. Por meio de arte e criação, a intenção é incentivar possibilidades de sustento próprio e familiar digno, com preocupação de produção socialmente sustentável, e, em um escopo mais largo, ajudar na trajetória de efetiva descriminalização de raça, gênero e classe.

\footnotetext{
${ }^{9}$ Segundo trecho de uma ata de reunião do Coletivo na qual elas debateram sobre definições de apresentação para o projeto para as egressas.
}

Em busca de um local de acesso comum às egressas, o Coletivo em Silêncio fez uma parceria com a direção do Patronato Margarinos Torres, órgão pertencente à Secretaria do Estado do Rio de Janeiro de Administração Penitenciária (SEAP).
"É uma Instituição pública destinada a realizar o cumprimento dos benefícios penais de: Liberdade Condicional (LC), Sursi, Prisão Albergue Domiciliar (PAD), Prisão Albergue Domiciliar Monitorada (PADM), Limitação de Final de Semana (LFS) e Prestação de Serviços à Comunidade (PSC)." (Governo do Estado do Rio de Janeiro) ${ }^{10}$

Por receber egressos e egressas do sistema prisional frequentemente, o encaminhamento de mulheres que pudessem participar do projeto é facilitado por essa parceria. O primeiro contato é feito diretamente no Patronato, que cede um espaço ao Coletivo para captar interessadas nas propostas. Além de estreitar o caminho até o público alvo, a instituição também disponibiliza salas para aulas teóricas e oficinas práticas.

\section{Design aplicado às necessidades do projeto}

O papel do designer em um projeto como esse é identificar e mediar as necessidades das mulheres e do Coletivo. O intuito nesse caso é enxergar as mulheres em uma situação de extrema vulnerabilidade social e produzir para as mesmas: mulheres encarceradas que são diariamente esquecidas pela sociedade que as cerca e pelo Estado responsável pela sua "correção comportamental" eficaz.

Por meio de leituras de pautas de reuniões antigas, acompanhamento de discussões e pequenas entrevistas com as integrantes do Coletivo em Silêncio, mostrou-se imprescindível a criação de uma identidade visual e uma estratégia de comunicação que contemplassem o

\footnotetext{
${ }^{10}$ SEAP: Patronato Margarinos Torres. Disponível em:

http://www.rj.gov.br/web/seap/exibeconteudo? article -id=1484134. Consultado em junho de 2017.
} 


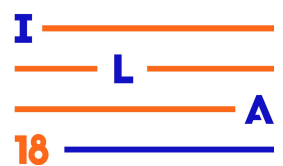

principal público-alvo do grupo: as mulheres egressas. Já o direcionamento que essa estratégia deveria seguir partiu de leituras de estudos sobre as mulheres encarceradas no Rio e questionamentos direcionados a pessoas que trabalhavam ou já havia trabalhado com esse público.

\subsection{Conceituação}

Além do projeto voltado para as mulheres egressas e a reconstrução de seus relacionamentos consigo mesmas e com a sociedade, o Coletivo em Silêncio também atua por meio de pesquisas, performances artísticas e outros trabalhos. Ele se apresenta como um espaço para que qualquer pessoa envolvida na temática dos cárceres corpóreos desenvolva suas ideias e projetos.

Dessa forma, o conceito para traduzir visualmente o Coletivo e aquilo que ele representa partiu da ideia de usar uma imagem que retratasse pequenos núcleos que se conectam num todo. Esses núcleos podem representar cada indivíduo, cada projeto desenvolvido, cada estudo e cada pauta de interesse trazidas para o grupo, sempre interligados através da construção coletiva. Também se mostrou importante que a marca ganhasse conotações de movimento, explorando a intenção do Coletivo de gerar transformação, especialmente por meio de expressão corporal.

\subsection{Desenvolvimento de marca}

Além da conceituação, mostrou-se pertinente trabalhar com elementos feitos manualmente. $\mathrm{O}$ fator manual agrega valor humano ao trabalho, assegurando ao público que um indivíduo participou ativamente da criação e desenvolvimento daquele projeto, criando proximidade - e até mesmo identificação - com os receptores dessa mensagem ${ }^{11}$.

${ }^{11}$ Josh Chen escreveu em "Fingerprint: The Art of Using Handmade Elements in Graphic Design" sobre a introdução de paixão e energia em um projeto por meio do uso, mesmo que pequeno, de elementos feitos a mão.
Diante disso, os estudos dos possíveis símbolos foram desenvolvidos com linhas, marcadores e canetas de ponta chanfrada, partindo de propostas previamente rascunhadas em um brainstorm visual (Figuras 1, 2, 3).

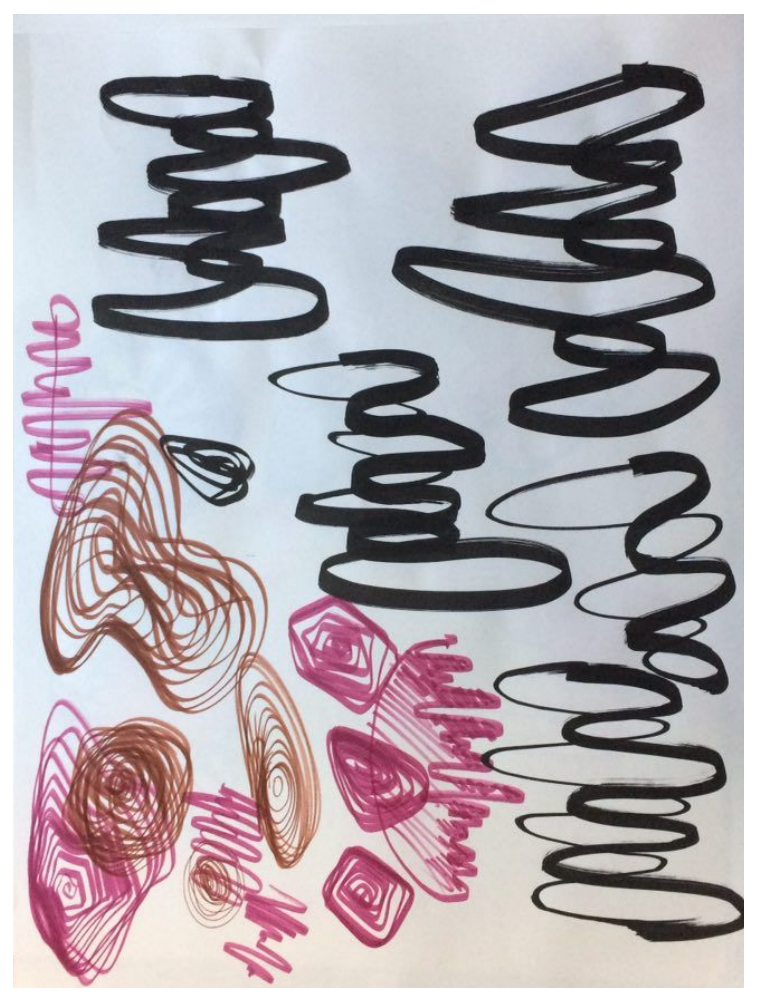

Figura 1 - Esboços

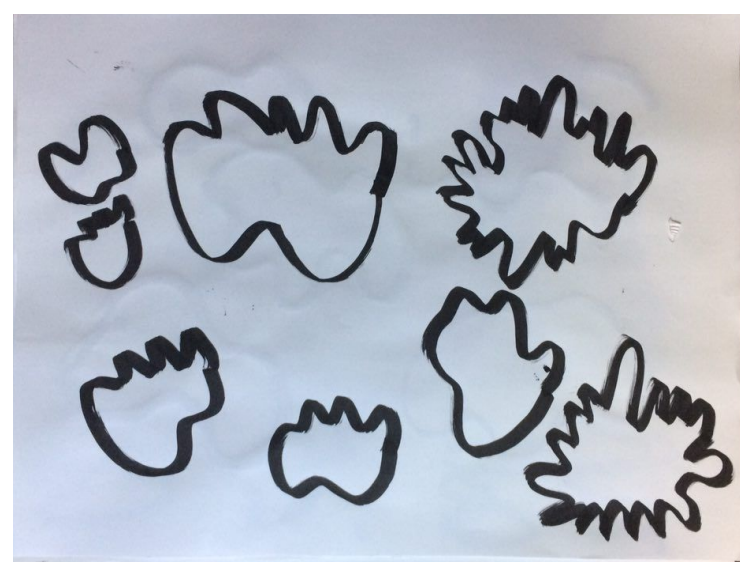

Figura 2 - Esboços 


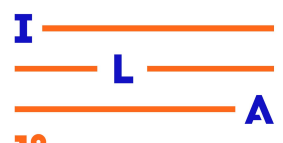

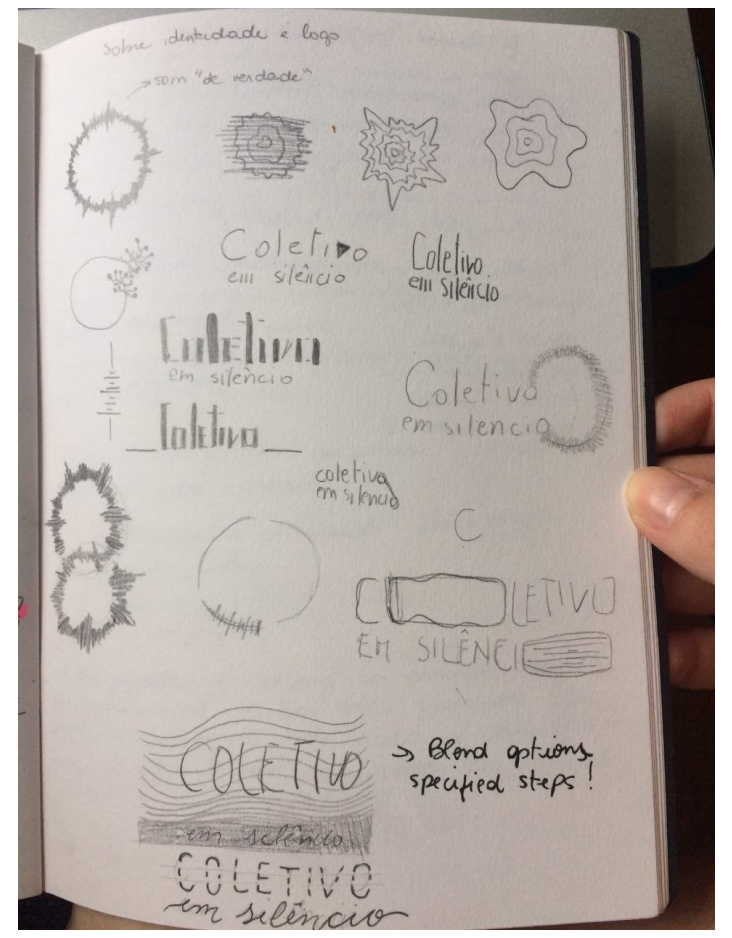

Figura 3 - Esboços

Desses estudos definiu-se uma representação de ondas (Figura 4) que não somente ilustra a ideia de núcleos diversos - representados pelas cristas e vales dessas ondas - conectados num todo e interagindo entre si, como também mostra essa imagem com um movimento próprio, reforçado pelas curvas e pela variação da grossura do traço.

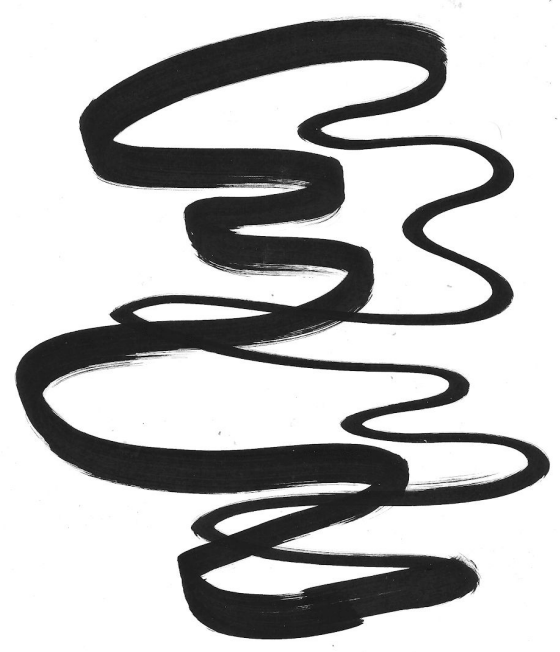

Figura 4 - Símbolo

A escolha das cores da marca (Figura 5), por sua vez, pretende reforçar a proposta de representação de pluralidade, diversidade, conexão com o próprio corpo e também com a natureza. A paleta principal, composta de amarelo, laranja, azul e verde, ilustram a variedade de etnias e corpos que podem ser encontradas na população feminina foco do Coletivo em Silêncio. Também introduz, de forma mais óbvia, elementos como terra, plantas e água à marca.
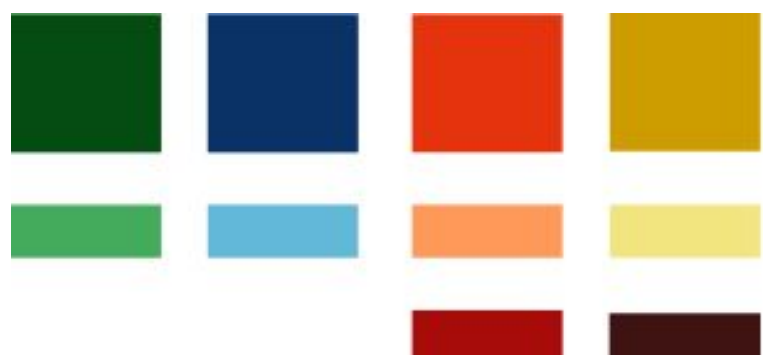

Figura 5 - Paleta de cores

É preciso destacar que evitou-se o uso de rosas e roxos, por serem cores que reforçam um estereótipo indesejado de gênero. Não era interessante para o projeto perpetuar o senso comum de que trabalhos envolvendo mulheres devem utilizar-se dessas cores para esclarecer a que público são direcionados, uma vez que o projeto deseja apresentar novas possibilidades e ajudar as egressas a encontrarem novas maneiras de se relacionarem consigo mesmas e com a sociedade.

Em conjunto com o símbolo da marca e suas cores, definiu-se também a tipografia para compor o logotipo. Antonio foi escolhida por ter curvas que dialogam de maneira harmoniosa com as ondas criadas para a marca. $\mathrm{O}$ resultado da união desses elementos cria uma marca de fácil legibilidade e reconhecimento (Figura 6).

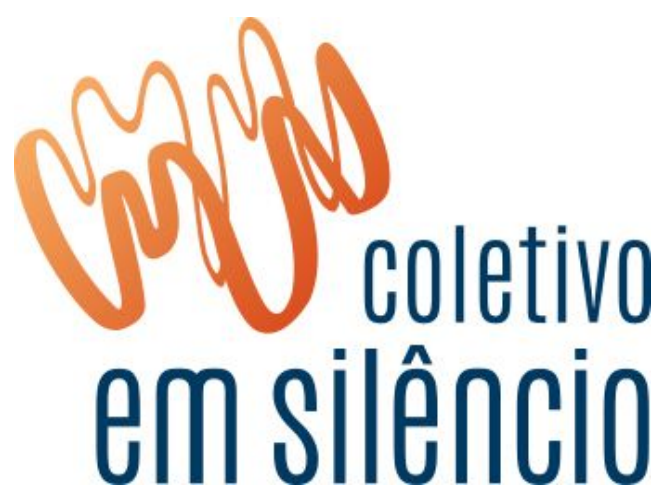

Figura 6 - Logo 


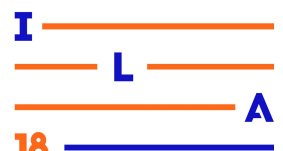

\subsection{Abordagem emocional na comunicação}

Para as mulheres em vulnerabilidade social se mostrou muito interessante que o material de comunicação fosse visualmente instigante sem que dependesse de textos para criar interesse no público. Isto porque essas mulheres muitas vezes possuem algum grau de analfabetismo, e porque esse grupo também é constituído, em pequena parte, por mulheres estrangeiras que não dominam o português.

Buscando alcançar essa atratividade, determinou-se que a melhor abordagem para esse público seria uma abordagem emocional. Projetou-se a criação de peças que causassem identificação, curiosidade e interesse nas egressas. Tais reações às peças são evocadas por meio do uso de elementos que trazem sentimentos de acolhimento e dignidade, na intenção de combater um comportamento comum no público-alvo de que elas não são dignas de novas oportunidades ${ }^{12}$.

Dessa forma definiu-se um estratégia de comunicação especialmente para o primeiro contato que o Coletivo terá com essas mulheres considerando que o espaço para a captação de egressas interessadas no projeto seria uma sala no Patronato.

As peças criadas para tal estratégia buscam, principalmente, a construção de vínculos afetivos entre as egressas e o Coletivo. De acordo com as leituras em design emocional, esses vínculos podem favorecer o engajamento voluntário dessas mulheres com o programa, uma vez bem-sucedida a criação de memórias positivas e acolhedoras referentes a esse primeiro contato.

\footnotetext{
${ }^{12}$ Relatos orais obtidos da direção do Patronato e das próprias integrantes do Coletivo dizem que a maioria dessas mulheres acredita não merecer novas chances na vida, o que as faz evitar programas como, por exemplo, o pré-vestibular social. Por vezes esse sentimento de não merecimento é introduzido ou reforçado pela família elou companheiros das egressas.
}

Para isso, fotos de uma mulher negra clara (Figuras 7, 8, 9 e 10) foram produzidas e aplicadas em cartazes que seriam expostos no Patronato para gerar sentimento de identificação no público. Isto porque dados do Departamento Penitenciário Nacional (Depen) ${ }^{13}$ mostram que 68\% das mulheres presas no Brasil em 2014 eram negras. A modelo, por sua vez, se encontra em um ambiente aberto para desvincular a imagem da mulher a um espaço fechado, ao cárcere.

Ao entrarem em contato com essas fotos, as mulheres podem se projetar na posição de acolhimento e liberdade na qual a modelo se encontra, favorecendo a construção de uma primeira impressão positiva do projeto.

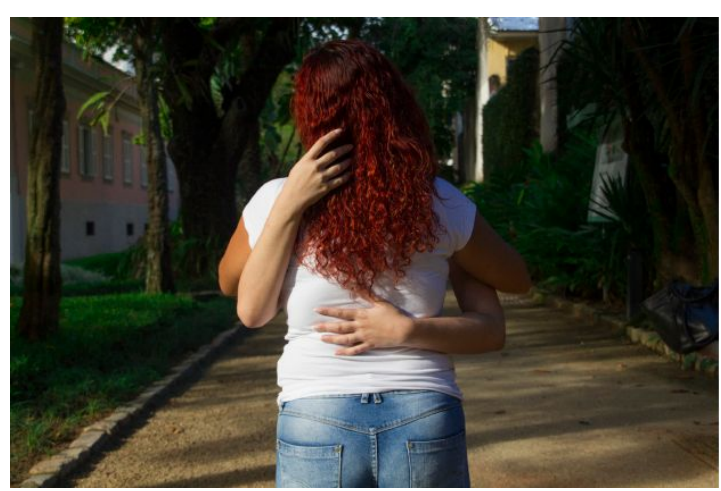

Figura 7 - Foto

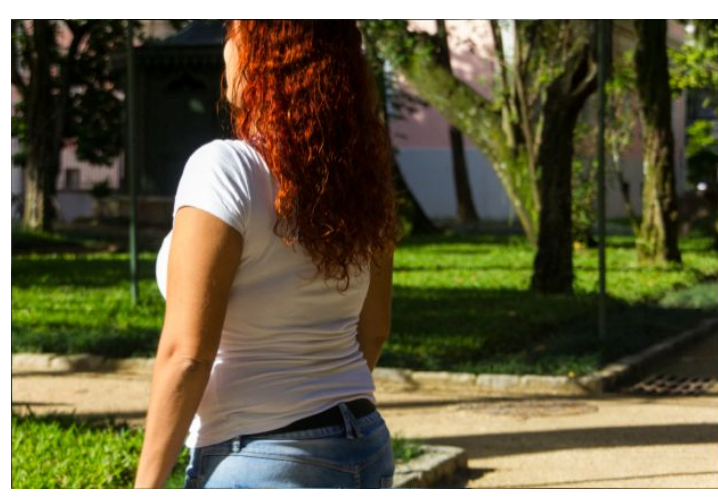

Figura 8 - Foto

${ }^{13}$ Retirado do Levantamento Nacional de Informações Penitenciárias Infopen Mulheres Junho 2014 

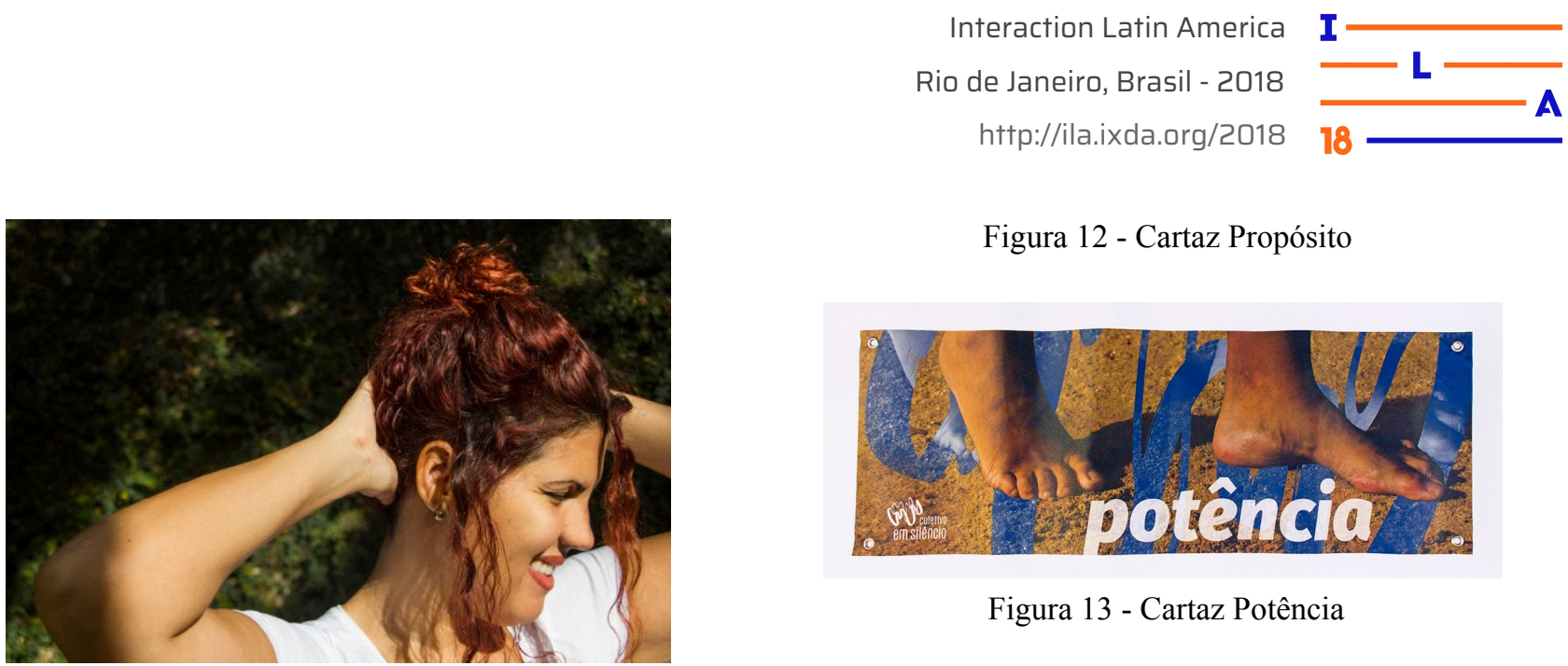

Figura 11 - Foto

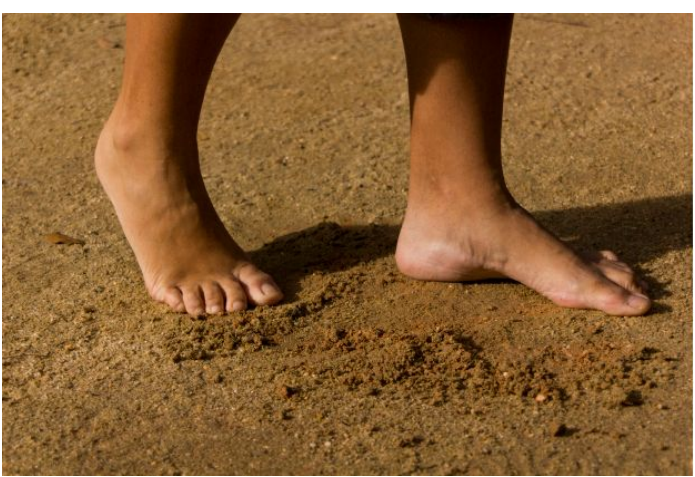

Figura 10 - Foto

Reforçando as fotos dos cartazes, também foram escolhidas palavras de incentivo às peças: Afeto, Propósito e Potência (Figuras 11, 12, 13 e 14). É importante ressaltar que essas palavras estão em coerência com os objetivos do Coletivo, mas também com o cuidado de se aproximarem de um vocabulário mais básico, para que fosse de fácil compreensão para aquelas que sabem ler. No entanto o recurso verbal não é imprescindível para a compreensão do cartaz.

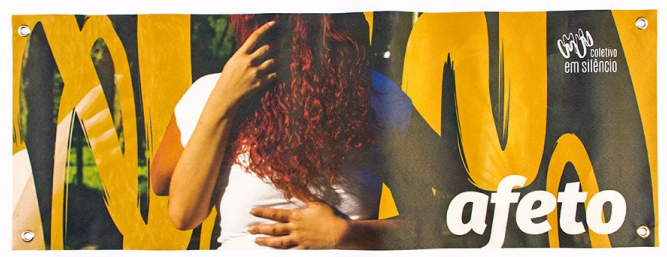

Figura 11 - Cartaz Afeto

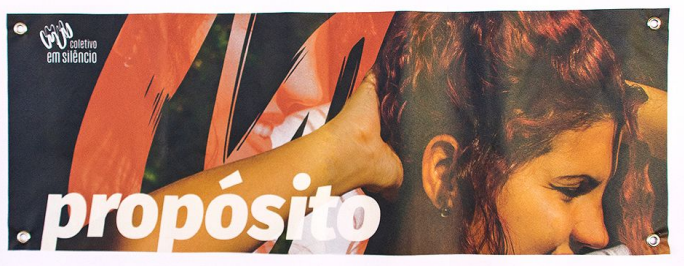

Figura 12 - Cartaz Propósito

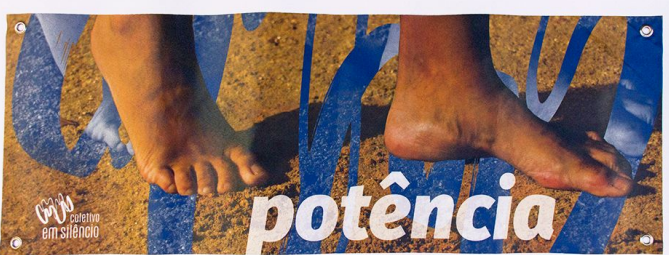

Figura 13 - Cartaz Potência

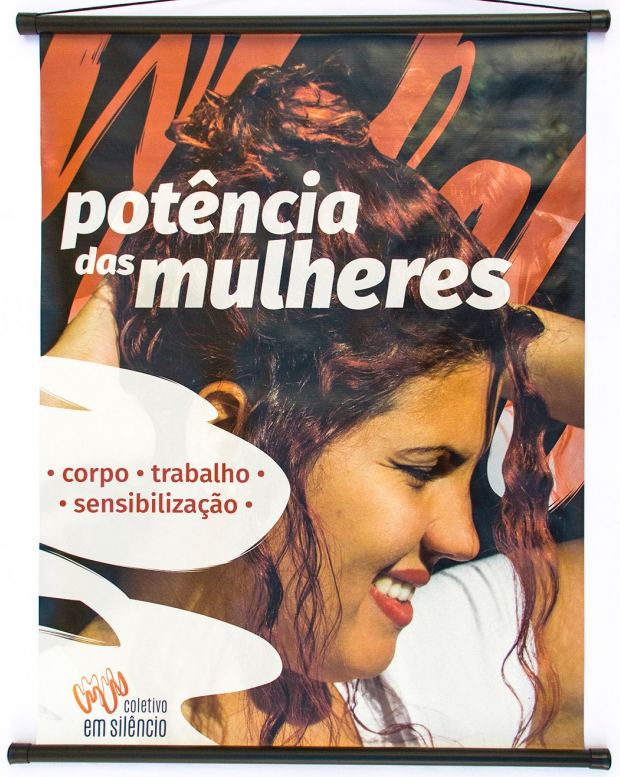

Figura 14 - Banner

Desenvolveu-se também uma mesa sensorial (Figura 15 e 16) com a intenção de estimular a egressa a interagir mais abertamente com uma integrante do grupo durante as conversas para captação de mulheres interessadas em participar do projeto. A mesa é composta de uma superfície costurada com enchimentos que traduzem o conforto e maciez dos corpos femininos. Propõe-se o uso dessa mesa sensorial como "quebra gelo", permitindo que a mulher se expresse através do tato e se envolva com as sensações que o toque nas partes macias podem trazer, criando um ambiente de acolhimento onde ela se sinta confortável para ouvir e dialogar com a representante do Coletivo. 


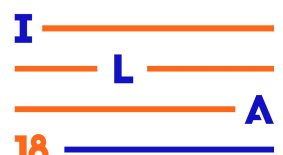

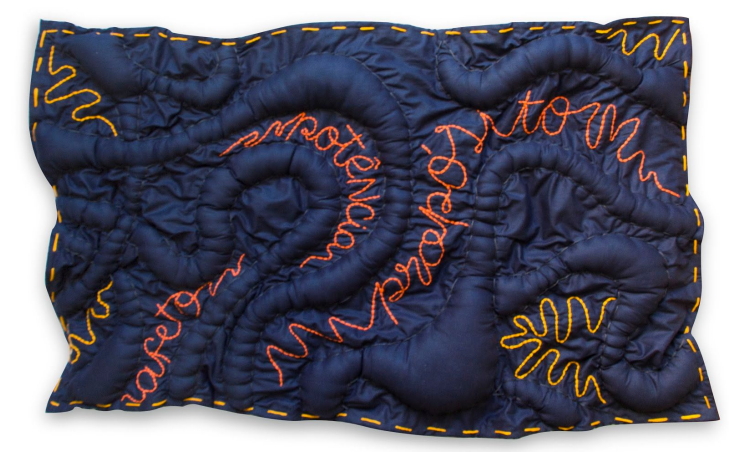

Figura 15 - Mesa sensorial

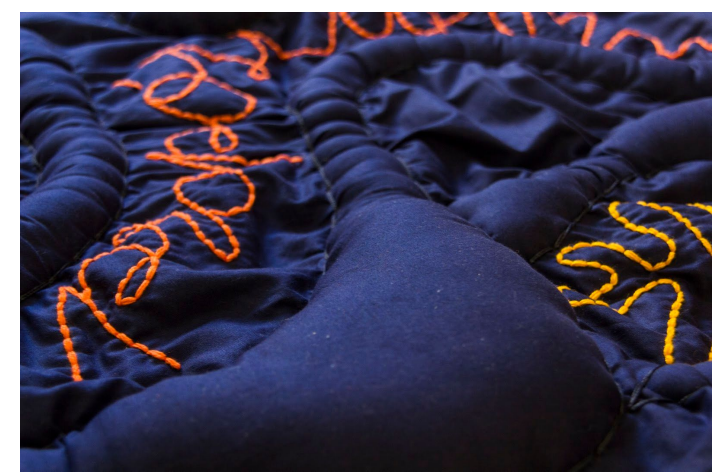

Figura 16 - Detalhe da mesa

Por fim, foram desenvolvidos um cartão de visitas e um carimbo (Figura 17) com o intuito de manter um laço com essas mulheres. Ambos poderão ser levados pela egressa quando o primeiro contato direto com o Coletivo se encerrar. Eles serão representantes que ativam a memória afetiva desse contato quando visualizados novamente em momentos posteriores, podendo ser utilizados como mais um reforço para incentivar a egressa a voltar e participar do projeto.

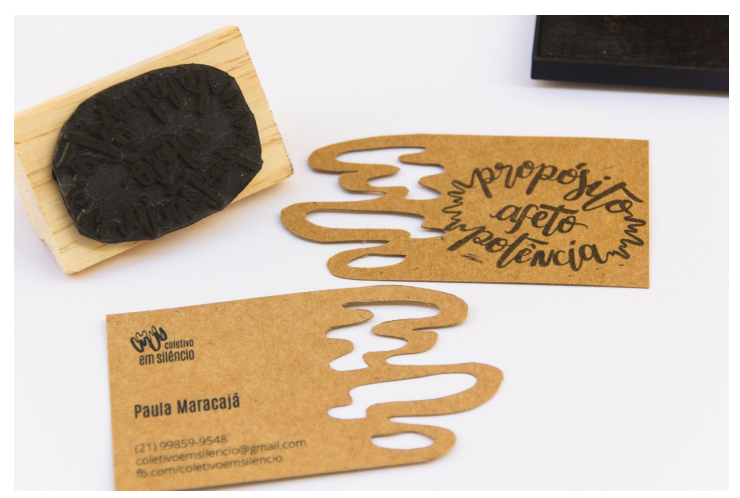

Figura 17 - Cartão e Carimbo

\section{Conclusão}

Entender as carências do Coletivo em Silêncio e equilibrá-las com as limitações e necessidades de um público extremamente vulnerável para garantir uma interação eficiente e, consequentemente, melhores resultados em um projeto como esse é só um exemplo da importância do envolvimento do designer no âmbito social.

Questiona-se, então, por que esse envolvimento ainda é raso, e não um mergulho de cabeça nas condições problemáticas da nossa própria sociedade em prol de revertê-las? Como aborda Victor Papanek (1985), o designer é responsável pelos erros ao nosso redor, às vezes por exercer maus hábitos na profissão, mas muitas vezes por não se envolver.

Diante de públicos e locais tão carentes de atenção, o design emocional e o design social são ferramentas que melhoram e valorizam o que se mostra como o trabalho mais importante do profissional da área: mediar interações interpessoais e com o meio em que vivemos para solucionar as mazelas da nossa sociedade.

\section{Referências Bibliográficas}

- Agência Juntos. Disponível em: http://www.agenciajuntos.com.br/. Consultado em maio de 2017.

- BOITEUX, Luciana; FERNANDES, Maíra; PANCIERI, Aline; CHERNICHARO, Luciana. Mulheres e crianças encarceradas: um estudo jurídico-social sobre a experiência da maternidade no sistema prisional do Rio de Janeiro. Laboratório de Direitos Humanos - UFRJ, 2015.

- BONSIEPE, Gui. Design, Cultura e

Sociedade. $1^{\text {a }}$ reimpressão. São Paulo: Blucher, 2013.

- BUCHANAN, Richard. Wicked Problems in Design Thinking. Design Issues, MIT, Vol. VIII, no 2, p. 5 - 21, Spring 1992.

- CAMPBELL, Alexandre; CASCARDO, Fabio; SERENO, Graziela; OLIVEIRA, Patrícia de; 


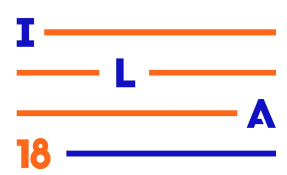

LIRA, Renata; ALVES, Vera Lúcia. Mulheres, meninas e privação de liberdade no Rio de Janeiro. ALERJ, 2016.

\section{- CHEN DESIGN ASSOCIATES. Fingerprint:} The Art of Using Handmade Elements in Graphic Design. How Design Books, 2006.

- FOCAULT, Michel. Vigiar e punir: nascimento da prisão. $37^{\text {a }}$ ed. Petrópolis: Vozes, 1987.

- FRASCARA, Jorge. People-centered design: complexities and uncertainties. Design and the Social Sciences. J.Frascara (Ed.), Taylor \& Francis Books Limited, 2002.

- IDEO.ORG. Field Guide to Human-Centered Design. $1^{\text {a }}$ ed. Canada: IDEO.ORG, 2015.

- LINDSTROM, Martin. Brand sense: a marca multissensorial. $1^{\mathrm{a}}$ ed. Porto Alegre: Bookman, 2007.

- NORMAN, Donald A. Design Emocional: por que adoramos (ou detestamos) os objetos do dia-a-dia. $1^{\text {a }}$ ed. Rio de Janeiro: Rocco, 2008.

- PAPANEK, Victor. Design for the Real World: Human Ecology and Social Change. $2^{\mathrm{a}}$ ed. London: Thames \& Hudson, 1985.
- PAZMINO, Ana Verônica. Uma reflexão sobre Design Social, Eco Design e Design Sustentável. Curitiba: I Simpósio Brasileiro de Design Sustentável, 2007.

- RIBEIRO, Camila Cardoso; PAES, Larissa Leme; REAL, Michelly Piacenso; SANTOS, Regina Claret Kapp; SAVAREZE, Solange Aparecida; DALANEZE, Sergio.

Ressocialização de detentas: Direitos humanos $X$ preconceito no contexto do CRF Rio Claro. Revista das Faculdades Integradas Claretianas, $\mathrm{N}^{\mathrm{o}} 6$, janeiro/dezembro, 2013.

- SANDERS, Elizabeth B.-N. From user-centered to participatory design approaches. Design and the Social Sciences. J.Frascara (Ed.), Taylor \& Francis Books Limited, 2002.

- SEAP: Patronato Margarinos Torres.

Disponível em:

http://www.ri.gov.br/web/seap/exibeconteudo?ar ticle-id=1484134. Consultado em maio de 2017.

- Shoot the Shit. Disponível em: http://www.shoottheshit.cc/. Consultado em maio de 2017. 